\title{
CALL FOR GLOBAL SOLIDARITY ON COVID-19 PANDEMIC from the InterAcademy Partnership (IAP)
}

The COVID-19 pandemic presents critical global challenges, affecting individuals, families, communities, health services and economies. These are extraordinary times and there is much to be done to collect, validate and use evidence: both to improve preparedness and responsiveness now and to improve our governance systems for the future. Research has already achieved a great deal: in identifying the virus, beginning to understand its epidemiology, characterising its clinical course, and providing the information to accelerate the development of new interventions - diagnostics, therapeutics and vaccines - although this will still take time. How should we make better and faster use of research and its outputs for our collective benefit, that is, the global public good? ${ }^{1}$ This Global Call from IAP emphasises the vital importance of doing more now to act collectively: effort on the global scale is essential to mitigate the spread of coronavirus in all territories.

The current global COVID-19 tragedy underscores the critical need for international collaboration across the scientific community and beyond, including open communication, shared resources and coordinated actions. We have seen the value of international scientific and other collaboration in past serious infectious disease outbreaks, for example, in tackling HIV $^{2}$, SARS ${ }^{3}$, Ebola and avian influenza ${ }^{4}$. Sustained strategies to tackle other major infectious disease threats, such as drug-resistant tuberculosis ${ }^{5}$ and antimicrobial resistance ${ }^{6}$ have also depended, and do still depend, on worldwide collaboration and concerted action. We must apply the lessons of what worked or didn't work in response to other threats, as well as learn from ongoing experience as this global pandemic unfolds so as to enable the best data-driven policies and programmes and to reaffirm collective endeavour now. ${ }^{7}$

Facts matter and leadership matters! Strong leadership supported by the best available medical and scientific information is vital. We must have coordinated national responses and international solidarity in sharing information and resources in responding to COVID-19, unhampered by antagonism between countries relating to perceived origins of the virus, by conspiracy theories and by stigmatising of minority groups. It is essential to avoid fragmentation in knowledge generation and disconnects in what should be a global COVID-19 strategy. If individual governments announce public health actions at variance with WHO advice, they should substantiate such initiatives by making available the advice on which their policies are based $^{8}$.

Deficits in international collaboration will be particularly deleterious for those who are most vulnerable, including countries with weaker health systems. Some low- and middle-income countries have yet to report many COVID-19 cases $^{9}$ but this will change and will have major consequences for those countries, their neighbours and for us all. Although WHO has a strategy for convening expertise and sharing information on global research and innovation on COVID- $19^{10}$ there is much to be done to ensure that this information does not lag behind rapid developments in the spread and impact of COVID-19, and that collective effort includes all relevant actions, engages with all relevant science, and shares all relevant outputs. WHO must also play a more powerful role in mandating and ensuring equitable access to the diagnostics, therapies and vaccines that will emerge. The scientific community can cooperate with WHO to achieve these objectives. IAP and its academies recognise the importance of supporting each country in communication with WHO in an open and responsible manner to support public health security worldwide.

Much about COVID-19 is uncertain but, to reduce uncertainty while building critical mass for sustained action, IAP urges:

1. All countries to renew their commitment to collaboration based on whole-of-government and whole-of-society approaches. Leaders in public health and governments must work together to fight the outbreak and there must be globalscale planning. IAP calls for renewed partnership efforts in research and innovation on COVID-19 between scientific institutions and others. The world must share expertise and resources: to improve understanding of the threat in its biological, clinical and societal dimensions; to identify and fill knowledge gaps; to develop new diagnostic tools; to identify and develop new or repurposed therapies; to accelerate progress in vaccine innovation and provision, and to monitor and evaluate the impacts of interventions. Identifying ways to expedite manufacturing, regulatory and supply-chain activities applies not just to novel interventions but also to the provision of personal protective equipment and other standard public health procedures. And it is vital to assess and manage the implications of COVID-19 and choices made on the provision of other healthcare and on other sectors essential for health, such as agriculture ${ }^{11}$. The urgency of the objectives demands unrelenting focus and unprecedented commitment to collaboration across all scientific disciplines and between the public and private sectors. There is no place now for promoting narrow commercial or national competitiveness and self-interest at the expense of others. Pathogens respect neither territorial nor ideological boundaries.

2. Coordination in the communication of validated information worldwide, by intergovernmental organisations and others ${ }^{12}$ is essential to enable strengthening of public health preparedness, informed by the best scientific evidence. 
Research outputs must also be deployed to increase the reliability and relevance of modelling the health and socioeconomic impacts and to avert unintended consequences, for example to supply chains. Better provision of science-based, robust advice is also essential to counter unproven assertions, prejudice and deliberate misinformation that otherwise acts to disrupt and destabilise civil solidarity and equity. The scientific community can and should show solidarity with others in promoting responsible, transparent and timely communication of credible evidence ${ }^{13}$. In addition, there are important social and behavioural questions to be addressed by research: for example, how to tackle anxiety, rumour and discrimination; how to involve communities in adhering to public health measures; and how to work with the media on communication ${ }^{14}$. Thinking further ahead, society must also be ready to pursue the options for decarbonising the economy when economic growth returns.

3. IAP recommends particular efforts to work with and support countries with weaker public health frameworks and health care systems, perhaps especially in Africa and Southeast Asia where coronavirus infections are expected to increase soon. IAP is committed to acting through its global network of more than 140 academies of science, engineering and medicine, together with the Global Young Academy and national young academies, to enable scientists in developing countries to draw on international scientific evidence to advise their own policy makers and citizens and to contribute to efforts worldwide in developing new interventions. The power of this global scientific resource, across all disciplines, is augmented by IAP implementing lessons for catalysing the sharing of good practice and building capacity, learned in previous interregional activities. IAP stands ready to work with WHO and other global and regional agencies to ensure that the best available scientific information is used to best effect, and this includes capitalising on advances at the frontiers of science and technology in the control of the virus, for example artificial intelligence and robotics. One initiative that IAP is proceeding in collaboration with others in the scientific and medical communities is the provision of web-based resources of curated, validated information contributed by academy members.

We conclude by reiterating that these are extraordinary times that demand global solidarity with coordinated effort informed by the best scientific evidence. IAP will do all it can to promote the sharing of expertise and good practice, and to catalyse action.

Signed by the members of the Steering Committee of the InterAcademy Partnership, March 2020

Volker ter Meulen, IAP President

Depei Liu, IAP President and co-chair, IAP-Health

Margaret Hamburg, co-chair, IAP-Health

Krishan Lal, co-chair, IAP-Science

Cherry Murray, co-chair, IAP-Science

Richard Catlow, co-chair, IAP-Policy

Masresha Fetene, co-chair, IAP-Policy
Notes

1. Pontifical Academy of Sciences "Responding to the pandemic, lessons for future actions and changing priorities" http://www.pas.va/content/ accademia/en/events/2020/coronavirus.html.

2. WHO "Global health sector strategy on HIV 20162021. Towards ending AIDS", 2016.

3. For example, Mackenzie et al. "The WHO response to SARS and preparations for the future" in Institute of Medicine "Learning from SARS: preparing for the next disease outbreak: workshop summary", 2004.

4. For example, Fidler "Global outbreak of avian influenza A (H5N1) and international law" American Society of International Law, 2004; Shu et al. "A ten-year China-US laboratory collaboration: improving response to influenza threats in China and the world, 2004-2014" BMC Public Health 201919 (Suppl 3), 520.

5. For example, Global drug-resistant TB initiative, www.stoptb.org/Wg/Mdrtb/default.asp; Balfour "Global collaboration formed to develop novel treatment regimens for TB" European Pharmaceutical Review 28 February 2020.

6. For example, WHO "Global action plan on antimicrobial resistance" www.who.int/ antimicrobial-resistance/global-action-plan/en; CDC "Combat antimicrobial resistance globally" www.cdc.gov./drugresistance/intl-activities.html; Goff et al. "A global call from five countries to collaborate in antibiotic stewardship: united we succeed, divided we might fail" Lancet Infectious Diseases 2017 17, PE56-E63;

7. WHO Global Preparedness Monitoring Board, www.who.int/gpmb; Academy of Medical Sciences UK, Medical Research Council and IAP "Interdisciplinary research in epidemic preparedness. Workshop report", 2019.

8. Editorial "Coronavirus: three things all governments and their science advisors must do now" Nature 2020, 579, 319-320.

9. WHO dashboard, https://experience.arcgis.com/ experience/685d0ace521648f8a5beeeee1b9125 cd.

10. See in particular (i) "Report of the WHO-China joint mission on coronavirus disease 2019 (COVID-19), 16-24 February 2020 and (ii) www. who.int/blueprint/priority-diseases/key-action/ novel-coronavirus/en.

11. "CGIAR's response to COVID-19", www.cgiar.org/ news-events/all-news/our-response-to-covid-19.

12. For example, World Health Summit COVID-19 Platform, www.worldhealthsummit.org/covid-19. html.

13. Calisher et al. "Statement in support of the scientists, public health professionals and medical professionals of China combatting COVID-19" Lancet 2020 395, e42.

14. Ghebreyesus and Swaminathan "Scientists are sprinting to outpace the novel coronavirus" Lancet 2020, 395, 762-764. 